\title{
The Effect Of Adlerian Group Counseling on Improving Counselor Trainees' Awareness of the Family of Origin
}

\author{
Hilma Fitriyani ${ }^{1 *}$, Gantina Komalasari ${ }^{2}$, Susi Fitri ${ }^{3}$ \\ ${ }^{1}$ Guidance and Counseling Graduate Program, Faculty Of Education Universitas Negeri Jakarta, Jakarta, \\ Indonesia, \\ ${ }^{2}$ Faculty of Psychology Universitas Negeri Jakarta, Jakarta, Indonesia, \\ ${ }^{3}$ Guidance and Counseling Postgraduate Program, Faculty Of Education Universitas Negeri Jakarta, Jakarta, \\ Indonesia, \\ ${ }^{*}$ Corresponding author. Email: hilma@unj.ac.id
}

\begin{abstract}
Possessing self-awareness of family of origin is important for counselor trainees because of usefulness in assisting counselees. This paper discussed the influence of Adlerian group counseling in increasing self-awareness on origin family for counselor trainees. The between-groups models pretest-posttest control group experimental research design was used while the samples were selected using purposive sampling. Hypothesis testing was conducted through the use of Wilcoxon signed rank test which was used to compare the posttest and pretest gain score between experimental and control groups. The results showed that $\mathrm{p}=0.007<0.05$ (significant). This means that counseling groups using an Adlerian approach increase counselor trainees' self - awareness of the family of origin.
\end{abstract}

Keywords: Adlerian, self-awareness, family of origin

\section{INTRODUCTION}

Corey \& Corey (2011) explained it is important for existing and prospective counselors to know the influence of self-awareness on family origin because many of the issues that counselees bring into the counseling room are rooted in childhood and growing experience in their family. In order to be an effective counselor, it is necessary to recognize how family origin and childhood have influenced their individual and professional life.

Prospective counselors need to be involved in activities that provide opportunities for self-exploration of their families. This is necessary to help them get awareness of their family of origin. However, Adlerian approaches are considered capable of achieving this because they pay great attention to individual lives. Corey (2009) pointed out that Adlerian pay attention to the patterns that people develop out of their relationships with their parents and siblings.

This approach looks at 3 things that are quite important in human life which are the development of individuals at the beginning of their lives (early recollection), constellations within the individual family, and the life task. The first is related to how environmental response at the beginning of an individual's life affects his or her behavior. Individuals need a situation that is friendly, supportive and full of encouragement instead of an authoritarian situation, full of violence and pressure. The second involves the socio-psychological configuration of a family. According to Adler (Corey, 2009), differences in birth positions will affect individual characteristics. This author found that the three universal life tasks that can help people fulfill their strong desires about being in unity with others and courageous in facing and dealing with life's problems are building friendships (social task), establishing intimacy (love/marriage task), and contributing to society (occupational task). They are important regardless of age, gender, time in history, culture, or nationality.

Self-awareness can be achieved in group counseling through the application of the Adlerian approach (Corey, 2009). Pieterse et al. (2013) define the term as a conscious state of thoughts, feelings, beliefs, behaviors, and attitudes. They also reveal that these factors are shaped by important aspects of individual social development and history. Whetten \& Cameron (2011) further describe, in more detail, the 5 important areas pointed out by Pieterse et al (2013) to include emotional intelligence, personal values, ways of thinking, attitudes toward change, and core self-evaluation. Considering the importance of family of origin awareness for 
counselor trainees in advancing their professional career, it is pertinent to research how it can be increased through the use of Adlerian approach by counselor trainees in group counseling on family origin.

\section{METHODS}

The between-groups models pretest-posttest control group experimental research design was used in this research. According to Heppner (2008), it involves random assignments of study participants into two or more groups, where one received treatment and the other acted as a control group.

Prospective counselors who are students of Guidance and Counseling at the State University of Jakarta made up the population for this study. The samples were selected through the use of a nonprobability purposive sampling method based on low or very low level of self-awareness (Creswell, 2012). Consequently, the number of the population that were selected based on this consideration was 24 students. However, Adlerian group counseling requires between 5 to 10 people (Sonstegard and Bitter, 2004). Therefore, 10 participants were selected for each of the two groups making all the total respondents used to be 20 . The counseling was held for 14 meeting sessions with a duration lasting between 90 to 180 minutes (Jacob, et.al., 2012).

\section{RESULT}

Based on the result of the pretest, it was discovered that there was an average difference of 0.85 in the scores of the two groups with the experimental having the highest with 85 points. Therefore, it was further tested through the application of the Wilcoxon signed rank test using SPSS 20.0 for windows which showed that $p=0.646>$ 0.05 . This means that there was no significant difference between the two groups. It was, therefore, concluded that they were equal in the score.

The posttest results revealed that there is an increase in score. The experimental and control groups showed a score increase of 1101 and 107 respectively. Wilcoxon was also applied in ensuring that there was no significant difference in the results for the two groups, and it found that $P=0.005<0,05$. This shows that there were significant differences.

Testing the quality of score increase through normalized gain revealed that the increase in the score of the experimental is in the medium qualification $=0.4$ while that of the control group is in the low qualification $=0.04$. This means that the quality of score improvement in the experimental is better than for the control group.

Hypothesis testing using Wilcoxon showed that $\mathrm{p}=$ $0.007<0.05$ (significant), such that $\mu 1 \neq \mu 2$. Therefore, Ha was ACCEPT while Ho was REJECTED. This shows that there is a difference in the average increase in the influence of self-awareness of family origin in prospective counselors that receive group counseling by using the Adlerian approach compare to those that do not. It can be deduced from this that the use of the approach is effective for the trainees.

The exploration process was conducted through 3 main Adlerian assessments including family constellation, early recollection, and life task. It is important to point out that Adlerian group counseling helps counselor trainees to identify the influence of family origin in their life by assessing the aforementioned in relation with building friendships (social task), establishing intimacy (love/marriage task), and contributing to the society (occupational task).

From the family constellation assessment, it was found that there were various existing conflicts in their families such as sibling rivalry, bad relation with father or mother, infidelity in the parent's marriage, and bad communication quality. 6 out of the 10 counselees reported a conflict between their parents which showed that there was no good coalition between father and mother in their marital relations which had an impact on the situation in the family. This indicates a dysfunctional family and according to Bitter (Corey dan Corey, 2011), its characteristics include closed communication, low self-esteem to one or both parents, rigid parenting pattern and rules, members of family expected to think, feel and act in the same way, control of family by parent by using fear, anger, punishment, guilt and power. This breaks the family and can lead to intensive stress level.

Interaction patterns, rules, values and conflicts within their families make counselees neglect their emotional state. This is influenced by low drive restricting them from obtaining freedom which is known as psychological reactance (Buboltz, et al., 2003). The results of research conducted by Buboltz, et al. (2003) show that the number of conflicts occurring within a family can be used to predict the low psychological reactance of individuals there. However, it was found in this research that counselor trainees do not have enough opportunities to explore their environment as a result of parents' perception that the world is unsafe thereby limiting the effective development of their children.

The respondents also revealed that a rule forbids that problems should not be shared beyond the family circle. This is founded on the idea that families need to help each other and that their inability to do that is dysfunctional. While relating the situation to the collective culture, Hampden-Turner \& Trompenaars 
(Whetten \& Cameron, 2011) assumed that group contributions are valuable. Therefore, seeking help from outsiders when there is any problem is considered dysfunctional, because of the weakness of family members to help each other.

Normalized gain test conducted for early recollection use showed that the quality of score improvement for the two groups is in a low category. However, the increase experienced in the control group is thought to be caused by the very small number of sessions, namely one meeting session. Research conducted by Statton (1990) showed that early recollection was successful when performed in ten weeks at 50 minutes per session.

It was also discovered that the lack of specific instructions that the counselee should write down important initial experiences can lead to the increase. Sweeney and Myers (1986) explained that early recollection is not a report or story about routines performed by individuals as a child, but a specific and clear story, with detailed memories. In many cases, it is necessary to use assessment of individual behavior, self-reports, use of standardized tests and other methods to cross-check and validate observations. By doing this, the exploration will be more profound and give the counselee the opportunity to see how the home family has influenced his childhood experiences and, consequently, his current personality.

Some of the counselees showed a meaningful initial experience with their father. Trusty, et al. (2004) explained that the characteristics of fathers have a positive effect on attractivity. Respondents with a good perception of their fathers have a higher level of social attractiveness which is portrayed in friendly traits, easily liked by others, able to run a social life and being a warm person. This research presents a contrary view because counselees have a poor perception of their fathers, which then reduces their social attractiveness. This reinforces Adler and Bowen's theory that a healthy initial experience in the family is the foundation for intimacy and objective emotional function in an individual's adult life (Nicholas and Schwart in Trusty, et al., 2004).

The results also showed that father and mother are two figures that are often raised in counselee's initial experience while in the study conducted by Statton (1990) at least 3 figures including mother, siblings and father were observed. The mother is the first figure that often reappears in individual early recollection because, according to Adler (Statton, 1990), the connection between mother and child mostly influences his or her potential. Siblings are considered second because of the influence they have when compared with their parents (Dreikurs in Statton, 1990).

The counselee was found to have been told about important events of his life that occurred in the house. This is in accordance with the results of Statton (1990) research that the important events at the beginning of individual life mostly occurred in the house settings. Sounders \& Norcross (Statton, 1990) also explained that the setting mostly mentioned in early recollection is the home environment. This supports what Sweeney stated (Statton, 1990) that the main influence in the development of individual personality is the family as the first social reality of children which is the source of how individuals interpret, perceive, conclude and generalize everything throughout their lives.

Life tasks results showed that the quality of the experimental group's score improvement in the high category can be an indication that counselees get good insights from the previous excavation process using family constellation and early recollection. This can make them become aware of things that affect their life's accomplishments, overcome such problems, and know areas that provide support and the ones experiencing dysfunction in their daily life. This is consistent with the research conducted by Guy (Chang $\& \mathrm{Chu}, 2001)$ that in terms of fulfilling work-related tasks, mental health workers choose their work based on the influence of family origin and early life experiences. These factors are related to the initial experience that gives emotional influence, parental characteristics, family relationships, and interaction pattern with other family members. Guy's explanation can be interpreted to mean that individuals will have a good awareness of their life's tasks when they recognize the influence of family origin and early life experiences.

The result of life task assessment showed that a counselee found it difficult to be friendly with others because of his father's influence while others feel that the education of living task is the most difficult to run compared to other life duties like love relationship which grows more with the education. In accordance with Way's explanation (Dreikurs \&Mosak, 1966) that many people struggle harder to solve problems relating to work because they feel it affects their existence. Love and marriage relationship problems are not prioritized especially when individuals are successful in their works.

Difficulties in conducting a life of friendship task were highlighted in this study because as Adler explained (Dreikurs \&Mosak, 1966), work-life related problems and love relationships could be overcome if individuals succeeded in carrying out the task of friendly living such as associating with others through friendship, social interest, and cooperation.

Difficulties in love relationships are also shown because counselees often find it difficult to control their nervousness when dealing with the opposite sex they like. This is in line with Adler's submission that emotion is an important tool in executing behavior (Sweeney, 2006). When individual emotional intelligence is influenced by how they perceive important experiences in their lives, it affects their 
ability or inability to express emotions in the right ways.

As regards value system, it was indicated that counselee has values in the form of obligations carried out in order to get approval. Dreikurs (Sweeney, 2006) explained that to be able to produce an equal life and overcome problems, values relating to obligations can be replaced with those of participation while consent can be replaced with self-respect and development. A counselee seems not to be doing this in his family and early days in life. He further explained that freedom can hardly be owned because of the parents' enormous desire to protect him which later leads to interference. However, it is difficult to materialize equality in his life because most parents still give preferential treatment based on gender.

The counselee difficulty in gaining freedom and achieving equality shows that there is no independence climate built by parents in the family. Referring back to the research conducted by Buboltz, et al. (2003), independence is a predictor of a high level of psychological reactance among family members. Therefore, if it is not prioritized, the level of psychological reactance among them will be low making them become passive about their freedom, and consequently having difficult feelings.

The counseling process was also able to help counselees recognize their attitudes toward the changes in their lives. Tolerance to ambiguity is one of these and it can be seen in the extent to which individuals can tolerate complex situations. Budner (Whetten \& Cameron, 2011) considered 3 situations capable of showing individuals' ability to face ambiguity, and they are novelty (tolerance for information or a new and unknown situation), complexity, (multiple, different information) and insolubility (problems that are very difficult to overcome, such as those whose alternative solutions are not expected, no information, or unrelated components of the problem). Therefore, some counselees can be considered to have a good ability to deal with ambiguous situations in their lives.

For example, one of the counselees with severe illness who must undergo a long and heavy treatment is in a situation where he must be able to tolerate a new and unknown situation which is then exacerbated by the lack of adequate support and ignorance from the family which made him feel very bad with the pain he was experiencing and entered another situation where the components of his problem are not related to each other. He managed to overcome it by entering positive thoughts such as others who have diseases heavier than his own. Analyzing this counselee reveals that he managed to get out of one of the basic things that affect individual behavior such as the wrong perception that life is difficult and demanding (Mosak \& Maniacci in Corey, 2009).
One of the counselees required a long time to overcome ambiguous situations in his life because he was attacked by his mother for sharing his problems with his childhood friend against the rules of the family. explained that during counseling he was able to fight himself to do what he considered good and released himself from the shackles of his mother's teachings which were quite confusing regarding sharing behavior. The counseling process was also considered to have helped him get away from one of his basic mistakes which involve seeking approval of himself from everyone and lack of security (Mosak \& Maniacci in Corey, 2009) which makes him take all forms of responsibility that often made him feel very exhausted. The counselees also recognized the fundamental evaluations of people about them. They understand they have both positive and negative things in their lives and that most alleged negative things apparently come through reciprocity and not specifically from them according to other members of the counseling group. This reality gives them a positive feeling and, consequently, positive evaluations.

\section{CONCLUSIONS}

The results showed that group counseling through the application of Adlerian approach effectively increased counselors trainees' self-awareness about their family. It also revealed that there is a significant difference between the gain score of the experimental and control groups with the quality of increasing scores in the experimental better than those in the control group.

Prospective counselors must be given this opportunity in order to help them realize the influence of family origin on their current life and also to avoid the possibility of a counter-transference in the counseling process that will be held in the future. In addition, group counseling held in form of personal therapy can help prospective counselors have a healthier psychological life and give them the opportunity to learn directly about the counseling process.

However, it is recommended that subsequent research should improve on the number of group members, and attention should be placed on individual variables that affect self-awareness, such as intelligence, age, gender, experience of counseling and education level. Physical and mental health status of the respondents must also be focused on when using the instrument of self-awareness to influence family of origin as developed in this study. 


\section{REFERENCES}

[1] Buboltz Jr., W,C, Jhonson, P., \&Woller, K,M,P., 2003. Psychological Reactance in College Students: Family of Origin Predictors. Journal of Counseling\&Develpoment, 81, $313-317$.

[2] Chang, Ching-jan\& Chu, Yu-wei. 2001. Measuring Early Family Experiences: The Validity and Reliability of The Chinese Family-of-Origin Scale (FOS). Journal of Counseling Changhua Normal University Guidance Journal, 22, 231-258.

[3] Corey, G., 2009. Theory and Practice of Counseling and Psychotherapy. Belmont: Brooks/Cole.

[4] Corey, M,S, \& Corey, G., 2011. Becoming a Helper (6th ed.). Belmont: Brooks/Cole.

[5] Creswell, J.W. 2012. Educational Research: Planning, Conducting and Evaluating Quantitative and Qualitative Research (4th ed). Boston: Person Education Inc.

[6] Dreikurs, R, \&Mosak, H,H,. 1966. The Task of Life I. Adler's Three Task. Alfred Adler Institute of Chicago. Retrieved fromhttps://adlerprod.s3.amazonaws.com/uploads/resource/filename/ 323/The_Tasks_of_Life_I-Dreikurs-

Mosak_Individual_Psychologist_1966_4_1_.pdf on 10thFebruary 2017.

[7] Heppner, P,P., Kivlighan, D,M,\&Wampold, B,E,. 2008. Research Design in Counseling, 3rd Edition.Belmont : Thomson Brooks/Cole.

[8] Jacobs, Ed,E,. Masson, R,L,. Harvill, R,L,.\& Schimmel, C,J,. 2012. Group Counseling Strategies and Skills 7th Ed. Belmont: Brooks/Cole.

[9] Pieterse, A,L,. Lee, M,.Ritmeester,A,.\& Collins, N,M,. 2013. Towards a Model of Self-Awareness Development for Counselling and Psychotherapy Training. Counselling Psychology Quarterly, 26 (2), 190-207.

[10] Sonstegard, M,A,. \& Bitter, J,R,. 2004. Adlerian Group Counseling and Therapy (Step-by-Step). New York: Brunner-Routledge.

[11] Statton, J,E,P,. 1990. Adlerian Counseling and The Early Recollection of Children. Proquest Dissertations \& Theses Full Text : The Humanities and Social Science Collection.

[12] Sweeney, T,J,. 2006. Adlerian Counseling and Psychotherapy: A Practitioner's Approach 5th ed. New York : Taylor \& Francis Group.

[13] Sweeney, T,J. \& Myers, J,E,. 1986. Early Recollections: An Adlerian Technique with Older People. The Clinical Gerontologist, (4), 3-12.

[14] Trusty,J,. Skowron, E,A,. Watts, R,E, \&Parrilo III, A,L,. 2004. Modelling the Effects of CounselorTrainees' Perceptions of Early Childhood on Trainees' Social Influences Attributes. The Family Journal: Counseling and Therapy for Couples and Families, 12(1), 6-13.

[15] Whetten, D,A,. \& Cameron, K,S,. 2011. Developing Management Skills. New Jersey: Pearson Education, Inc. 